\title{
Multi-criteria approaches to electric power system development
}

\author{
Nikolay Belyaev ${ }^{1, *}$, Andrey Egorov ${ }^{1}$, Nikolay Korovkin ${ }^{2}$ and Vladimir Chudny ${ }^{2}$ \\ ${ }^{1}$ JSC «Technical Inspection UES», Russia \\ ${ }^{2}$ Peter the Great St.Petersburg Polytechnic University, Russia
}

\begin{abstract}
The paper considers the issues of multi-criteria optimization procedure when planning the development of electric power systems (hereinafter - EPS). The advantages of multi-criteria approach as compared to the standard statement of a problem dealing with the justification for EPS development and feasible criteria for such a development have been examined. The problem of optimization of the structure of generating capacities within the power system has been stated and solved on the basis of four criteria; the analysis of obtained results has been carried out.
\end{abstract}

\section{Introduction}

Current conditions of electric power development in the world feature increasingly stringent requirements for electric power system (hereinafter - EPS) safety and quality of power supply to consumers, which is due, on the one hand, to economically reasonable trends dealing with deepening electrification of the economy and households (including the introduction of modern production technologies and digitalization of technological processes), on the other hand, to the growth of social and economic importance of reliable electric power supply, especially in big and metropolitan cities. In this case, strong restrictions are imposed on the development of energy engineering in respect of price and tariff consequences of adopted investment decisions that are also due to socio-economic factors expressed in restraining the increase of electricity and demand capacity prices.

Under these conditions the problem arises to enhance the efficiency of planning the development of power engineering industry so as to reduce the costs of meeting growing demand for electric power and capacity. At the same time, a large number of other requirements are imposed on EPS development, including those related to the reliability and safety, adverse environmental impact restrictions and others. This determines the complex nature of the task of EPS development justification which requires the elaboration of appropriate methods for its solution.

\section{Multi-criteria approaches to validate the EPS development}

The standard problem statement of electric power systems (EPS) planning justification is to minimize the overall reduced costs $C$ connected with electric power supply to consumers [1]:
$C(\mathbf{x})=\sum_{t}\left(C_{t}^{K}(\mathbf{x})+C_{t}^{O}(\mathbf{x})\right) \cdot(1+d)^{-t} \underset{\mathbf{x}}{\longrightarrow} \min$,

$\mathbf{x} \in R$,

where $C_{t}^{K}, C_{t}^{O}$ - capital and operational costs per year $t$ respectively, $d$ - discount rate. Variables $x$ in problem (1) are engineering solutions of planning electrical generation, transmission and distribution systems. Each solution exhibits performance indicators including their cost-based value and structure. The range of limitations $R$ is specified by EPS reliability and security requirements influencing the choice of certain engineering solutions or their combinations. Such limitations include both EPS power equipment process constraints and EPS performance as a whole.

The statement (1) reflects the principle of minimizing the cost of electricity supply to consumers while meeting mandatory requirements for the performance of power systems. One of the issues of statement (1) is the complexity of describing the range of limitations $R$. If the constraints related to the modes of EPS equipment operation are usually determined unambiguously, the restrictions imposed on the operation of the EPS as a whole are in some cases objectively difficult to set with fixed values of corresponding indicators.

Such restrictions, for example, include a required level of EPS reliability. Theoretically, the required level of EPS reliability is justified taking into account the cost of reliability (redundancy) and unreliability damages (power supply interruptions and under-supply) [2]. In practice, this approach is not feasible due to the variety of consumers of EPS and the lack of unambiguous assessments of such damages. Similarly, it is difficult to uniquely determine restrictions on EPS environmental impact, since such restrictions are set for the industry as a whole, and not only for electric power facilities. In this regard, it is advisable to translate some of the constraints that form the range $R$ in problem (1) into additional functions. Thus, the statement (1) is transformed into a 
multi-criteria problem.

An example of the problem given in [3] exhibits the advantages of such an approach. A two-criterion optimization of the structure of EPS generating capacities has been performed: low costing minimization and minimization of capacity shortage probability $J_{D}$ :

$$
\begin{aligned}
& C(\mathbf{x}) \stackrel{\mathbf{x}}{\longrightarrow} \min , \\
& J_{D}(\mathbf{x}) \stackrel{\mathbf{x}}{\longrightarrow} \min , \\
& \mathbf{x} \in R .
\end{aligned}
$$

Various types of generating equipment have been studied during optimization, including nuclear and hydroelectric power plants, units of thermal power plants of various types and different unit capacity. Technical and economic indicators and reliability indices of generating equipment have been accepted according to reference data. The results of solution (2) are shown on Fig. 1.

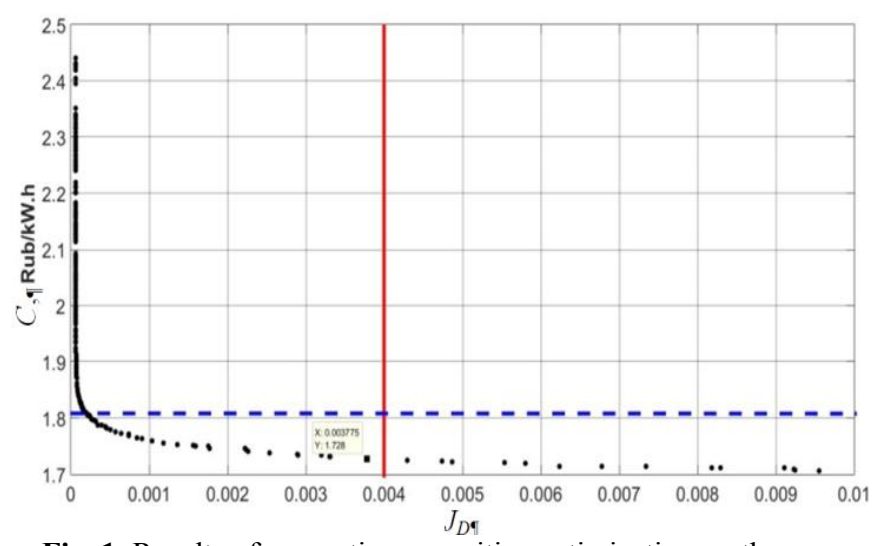

Fig. 1. Results of generating capacities optimization on the basis of two criteria.

On Fig. 1 the values of target functions (2) are plotted on axes: on horizontal line - probability of capacity shortage, on vertical line - working cost of electric energy compatible with accumulated total costs. Points mark the results. The total number of obtained solutions is equal to 375 .

At regulatory restriction equal to $J_{D} \leq 0,004$ [2] one should obtain, while solving the problem in statement (1), the result compatible with minimum costs under condition of meeting the restriction marked with tag on Fig. 1 ( $\left.c=1,73 \mathrm{Rub} . / \mathrm{kW} \cdot \mathrm{h}, J_{D}=0,0037\right)$. However, this option does not seem to be optimal if other solutions given on Fig. 1 are examined. For example, an insignificant price increase within $1 \mathrm{cop} . / \mathrm{kW} \cdot \mathrm{h}$ allows reducing $J_{D}$ to the level of 0,00226 and increasing the price by 5 per cent as compared to the solution marked on Fig. 1 (up to $1,81 \mathrm{Rub} . / \mathrm{kW} \cdot \mathrm{h}$, shown by horizontal dot lines) allows reducing $J_{D}$ up to 0,00016 , i.e. more than by an order of magnitude.

Thus, the introduction of the second criterion into (2) allows not only considering regulatory requirements for $J_{D}$ value, but also choosing its optimal value with respect to the assessment of incremental costs with due account made for a specific EPS structure and its feasible engineering solutions.

\section{Problem statement}

Let us consider the problem of EPS generating capacities optimization taking into account four criteria:

$$
\begin{aligned}
& C(\mathbf{x}) \longrightarrow \mathbf{x} \min , \\
& J_{D}(\mathbf{x}) \stackrel{\mathbf{x}}{\longrightarrow} \min , \\
& W_{F}(\mathbf{x}) \longrightarrow \mathbf{x} \min , \\
& P_{M A X}(\mathbf{x}) \longrightarrow \mathbf{x} \min , \\
& \mathbf{x} \in R .
\end{aligned}
$$

where $W_{F}$ is a share of electric power generated at thermal power plants, $P_{M A X}$ is a maximum share of one type of generating capacities in the structure of installed capacity.

Thus, the first criterion in (3) features the principle of cost minimization, the second one is the reliability maximization criterion, the third criterion shows the environmental impact minimization, and the fourth one may be considered as one of energy security criteria.

Variables in the problem are discrete values $x_{k, i} \in \mathbf{x}$, corresponding to the number of units (power units) of power plants of type $k$ in node $i$. The above types of units (power units) of power plants are presented in Table 1. Performance indicators necessary for calculating target functions are set for each of them (available capacity, technological minimum, design factor of installed capacity use, amount of capital and operating costs, forced outage rate, probability of emergency outages) according to reference and design data. The parameters of EPS energy demand should be set as initial data as well. The following parameters of electricity demand in EPS should be also set as initial ones: forecast power consumption, maximum and scheduled electric load, indicators of irregular load deviations with details for EPS nodes.

Zone $R$ is described by the following limitations:

maximum or minimum possible (with account made for existing EPS structure and solutions adopted for implementation) number $\left(\underline{x}_{k, i}, \bar{x}_{k, i}\right)$ of each type of units (power units):

$$
\underline{x}_{k, i} \leq x_{k, i} \leq \bar{x}_{k, i},
$$

total volume of generating capacities specified as a required value of maximum electrical load $N_{\max }$ :

$$
\sum_{i} \sum_{k} P_{k} x_{k, i} \geq N_{\max }, \quad k \in G,
$$

where $P_{k}$-available unit (power unit) capacity of $k$ type,

technical constraints of total capacity $\left(\underline{P}_{k, i}, \bar{P}_{k, i}\right)$ of certain types of power plants: as per technological minimum, fuel supplies, required volume of thermal energy supply (for TPP) etc.:

$$
\underline{P}_{k, i} \leq P_{k} x_{k, i} \leq \bar{P}_{k, i} \text {. }
$$


Table 1. Structure of power plant units (power units).

\begin{tabular}{|c|c|c|c|c|c|}
\hline Type & Name & $\begin{array}{c}\text { Avai- } \\
\text { lable } \\
\text { (maxi- } \\
\text { mum) } \\
\text { capacity, } \\
\text { MW }\end{array}$ & $\begin{array}{c}\text { Tech- } \\
\text { nolo- } \\
\text { gical } \\
\text { mini- } \\
\text { mum, } \\
\text { MW }\end{array}$ & $\begin{array}{c}\text { Specific } \\
\text { capital } \\
\text { costs, th. } \\
\text { Rub/kW }\end{array}$ & $\begin{array}{c}\text { Specific } \\
\text { opera- } \\
\text { tional } \\
\text { costs } \\
\text { Rub/ } \\
\mathrm{kW} \cdot \mathrm{h}\end{array}$ \\
\hline TPP & ST-100 & 100 & 80 & 50 & 0,70 \\
\hline CTPP & CTST-600 & 600 & 360 & 50 & 0,60 \\
\hline CTPP & CCP-150 & 150 & 60 & 60 & 0,77 \\
\hline CTPP & CCP-450 & 450 & 180 & 50 & 0,73 \\
\hline CTPP & CCP-800 & 800 & 240 & 40 & 0,69 \\
\hline CTPP & GT-100 & 100 & 0 & 60 & 1,17 \\
\hline HPP & $\begin{array}{c}\text { Hydraulic } \\
\text { unit-100 }\end{array}$ & 100 & 15 & 170 & - \\
\hline HPP & $\begin{array}{c}\text { Hydraulic } \\
\text { unit-300 }\end{array}$ & 300 & 30 & 140 & - \\
\hline NPP & $\begin{array}{c}\text { LWGR- } \\
1200\end{array}$ & 1200 & 1200 & 110 & - \\
\hline WG & WG-50 & $*$ & $*$ & 150 & - \\
\hline
\end{tabular}

* to be specified as probability distribution series

\section{Problem solution}

Modern multi-criteria optimization schemes including for the purposes of solving the problems of power engineering industry are well known [4]. In terms of solution formalization while adopting multi-criteria optimization it would be of interest to range the variety of Pareto optimal solutions obtained as optimization results and to choose specific solution options for their implementation. Approaches [5] applied as of today are based at all events on expert opinions that propose, for example, importance ranking tests of criteria or assignment of weighting factors to criteria.

The application of up-to-date evolutionary algorithms, such as genetic algorithm, ABC or BAT techniques widely used for solving discrete problems of overall optimization, including those for related branches [6], is an advanced trend of optimization problem solution for the purpose of EPS development justification. The above algorithms use the targeted iteration and are in line with probabilistic approaches of EPS development planning that currently apply random iteration (Monte-Carlo techniques). It is anticipated that the use of the above algorithms will significantly enhance the efficiency of EPS development justification [7].

To solve the problem (3) a genetic algorithm is proposed for application, its main provisions are presented in [4] with respect to branch problems. The calculation of target functions at each algorithm step is carried out by applying Monte-Carlo technique in the following way:

1. For each defined solution option with the use of random number generator, a set of random EPS states is considered, taking into account scheduled outages and emergency repairs of EPS equipment, regular and irregular load changes, available EPS power changes of seasonal and stochastic nature on the basis of indicators given as source data. The following should be specified for each described state: working capability of power plants in nodes, load for customers in nodes, transmission capacity of connections between nodes. Similarly, operating deviations of performance indicators with respect to expected (predicted) values can be taken into account.

2. For each random state, the problems of capacity shortage minimization as well as those of operational costs minimization (by optimizing power balance) should be solved in the way presented in [3]. First of all, the problem of capacity shortage minimization is to be solved as a high priority problem in terms of reliable consumers' supply. The optimization of power plant load according to specific operational costs is to be performed for consumers' demand got as a result of problem solution.

3. Following the results of consideration of all random states, the values of target functions (3) are defined for formulated solution option:

$$
J_{D}=\frac{S_{D}}{S},
$$

where $S_{D}$ is the number of random states with capacity shortage, $S$ is the total number of random states;

$$
C=\frac{\sum_{t}\left(C_{t}^{K}+\frac{1}{S} \sum_{s} C_{t, s}^{O}\right) \cdot(1+d)^{-t}}{\sum_{t} W_{t} \cdot(1+d)^{-t}},
$$

where $C_{t, s}^{O}$ are operational costs in random state $s$ per year $t, W_{t}$ is the electricity consumption per year $t$;

$$
W_{F}=\frac{1}{S} \sum_{s} \frac{P_{L F, s}}{P_{L s}},
$$

where $P_{L F, s}$ is the load of thermal power plants in random state $s, P_{L s}$ is the total load of power plants in random state $s$;

$$
P_{M A X}=\max _{k}\left(\frac{P_{k}}{\sum_{k} P_{k}}\right) .
$$

The total number of random states under consideration should ensure both a feasible accuracy of target functions calculation, primarily $J_{D}$, and generally a genetic algorithm convergence. As shown in [3], to get a solution of the problem under study, it is necessary to evaluate $\sim 10^{11}$ random EPS states.

According to the results of problem (3) solution, the variety of Pareto optimal solutions is specified. The calculations have been performed for EPS with maximum load of $12,87 \mathrm{GW}$ (the load curve irregularity factor being of 0,77 and the load factor - of 0,92 ). To carry out the calculations optional versions of EPS units (power units) have been accepted according to data of Table 1 while reliability indicators of generating facilities, including those of scheduled and emergency outages, are in line with data of [8]. The results are shown on Fig.2.

On Fig. 2 the cost value $C$ is plotted on horizontal axe, on vertical line - the value of $J_{D}$ (black mark), on 
additional vertical line - values of $W_{F}$ and $P_{M A X}$ (green and red marks respectively).

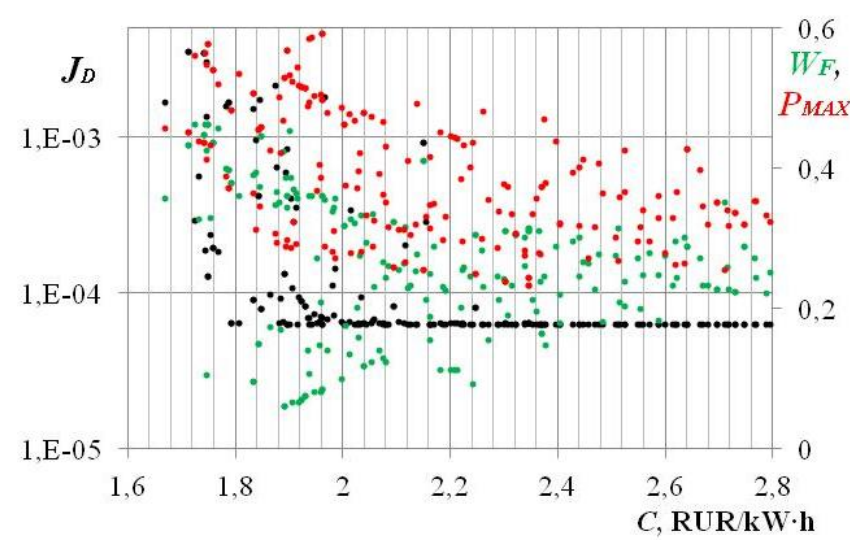

Fig. 2. Calculation results.

The results show that the minimum probability level of capacity shortage is achievable when costing $2 \mathrm{Rub} . / \mathrm{kW} \cdot \mathrm{h}$. At the same time, solutions with cost level within $2 \mathrm{Rub} . / \mathrm{kW} \cdot \mathrm{h}$ outline the conflict between two other criteria: so-called "eco-friendly" solutions (with the value of $W_{F}$ less than 0,2 ) have high values of $P_{M A X}$, which is due to a high share of nuclear power plants in the structure of generating capacities. On the contrary, solutions with relatively low values of $P_{M A X}$ feature high values of $W_{F}$ (at the level of $0,3-0,5$ ). To get a more favorable combination of these criteria, it is necessary to consider solutions with higher level of costs that involve the construction of wind and hydroelectric power plants. It means that should the last two criteria set as constraints in problem (3), depending on the choice of their values, the solutions in the area of low costs may be cut off and excluded from consideration.

The total number of solutions presented on Fig. 2 is 197, it makes difficult to analyze the results. The solutions with similar values of target functions may be put together by using well-known clustering algorithms [9]. The solutions shown on Fig. 2 are broken down into six groups, the findings are collected in Table 2.

Let us consider the groups of solutions obtained. The group 1 consists obviously of "eco-friendly" ("green") solutions non-expensive in this approach, where the values of $W_{F}$ do not exceed 0,1 and $C$ values $-1,93$ Rub./kW.h. In this case low values are mainly due to a large share $(>50 \%)$ of nuclear power plants in the structure of installed capacity ( 7 power units, 8400 MW). As a result, the values of $P_{M A X}$ are high. The total installed capacity for this group of solutions as compared to other solutions is minimal and relatively low values of $J_{D}$ are provided (no more than $10^{-4}$ ).

The group 2 compared to the group 1 exhibits the reduction of power units number in nuclear power plants and a substantial increase of the number of units in thermal power plants. This causes a marked increase of $C$ values (up to $1,98-2,12 \mathrm{Rub} . / \mathrm{kW} \cdot \mathrm{h}$ ). The group 2 shows better values of $P_{M A X}$ criterion in comparison with group 1 , but worse values of $W_{F}$, that may be explained by an increased share of thermal plants in the structure of installed capacity. It should be noted that in this group of solutions the number of wind power units varies significantly, they are used to increase the share of nonfuel power plants in electrical energy balance that results in $C$ increase but does not lead to a significant decrease of $W_{F}$ and $P_{M A X}$.

Table 2. Groups of solutions.

\begin{tabular}{|c|c|c|c|c|c|c|}
\hline Group No. & 1 & 2 & 3 & 4 & 5 & 6 \\
\hline \multicolumn{7}{|c|}{ Function values } \\
\hline$J_{D}$ & $\begin{array}{c}8 \cdot 10^{-5}- \\
10^{-4}\end{array}$ & $\begin{array}{l}7 \cdot 10^{-5}- \\
3 \cdot 10^{-4}\end{array}$ & $\begin{array}{l}2 \cdot 10^{-4}- \\
6 \cdot 10^{-4}\end{array}$ & $\begin{array}{l}9 \cdot 10^{-5}- \\
4 \cdot 10^{-4}\end{array}$ & $\begin{array}{l}6 \cdot 10^{-5}- \\
7 \cdot 10^{-5}\end{array}$ & $\begin{array}{l}6 \cdot 10^{-5}- \\
3 \cdot 10^{-4}\end{array}$ \\
\hline $\begin{array}{l}C, \\
\text { Rub./kW·h }\end{array}$ & $\begin{array}{c}1,83- \\
1,93\end{array}$ & $\begin{array}{c}1,98- \\
2,12\end{array}$ & $\begin{array}{c}1,73- \\
1,75\end{array}$ & $\begin{array}{c}1,84- \\
1,91\end{array}$ & $\begin{array}{c}1,94- \\
2,23\end{array}$ & $\begin{array}{c}2,09- \\
2,37\end{array}$ \\
\hline$W_{F}$ & $\begin{array}{c}0,06- \\
0,1\end{array}$ & $\begin{array}{c}0,32- \\
0,36\end{array}$ & 0,33 & $\begin{array}{c}0,15- \\
0,39 \\
\end{array}$ & $\begin{array}{c}0,08- \\
0,32 \\
\end{array}$ & $\begin{array}{l}0,2- \\
0,31 \\
\end{array}$ \\
\hline$P_{M A X}$ & $\begin{array}{c}0,51- \\
0,53\end{array}$ & $\begin{array}{c}0,26- \\
0,31\end{array}$ & $\begin{array}{c}0,43- \\
0,44\end{array}$ & $\begin{array}{c}0,29- \\
0,46\end{array}$ & $\begin{array}{c}0,33- \\
0,5\end{array}$ & $\begin{array}{c}0,23- \\
0,36\end{array}$ \\
\hline \multicolumn{7}{|c|}{ Generating capacities structure, ps } \\
\hline ST-100 & $0-3$ & $2-3$ & 2 & $2-3$ & $1-3$ & $1-3$ \\
\hline CTST-600 & 0 & $4-5$ & 2 & $1-5$ & $0-4$ & $1-7$ \\
\hline CCP-150 & $0-1$ & $0-2$ & $1-3$ & $0-1$ & $0-3$ & $0-3$ \\
\hline CCP-450 & $2-3$ & $2-4$ & 4 & $2-3$ & $2-4$ & $2-4$ \\
\hline CCP-800 & $1-3$ & 4 & $4-5$ & $2-4$ & $1-7$ & $2-5$ \\
\hline GT-100 & $3-4$ & $1-3$ & $6-13$ & $2-8$ & $3-47$ & $2-36$ \\
\hline $\begin{array}{c}\text { Hydraulic } \\
\text { unit-100 }\end{array}$ & $\begin{array}{c}10 ; 15 \\
20\end{array}$ & $10 ; 15$ & 10 & $\begin{array}{c}5,10 \\
15 \\
\end{array}$ & $\begin{array}{c}5 ; 10 \\
15 ; 20 \\
\end{array}$ & $\begin{array}{c}5 ; 10 \\
15 \\
\end{array}$ \\
\hline $\begin{array}{l}\text { Hydraulic } \\
\text { unit-300 }\end{array}$ & 10 & 10 & 0 & 10 & $0 ; 10$ & 10 \\
\hline $\begin{array}{c}\text { LWGR- } \\
1200 \\
\end{array}$ & 7 & 4 & 6 & $4-6$ & $5-7$ & $4-6$ \\
\hline WG-50 & $6-7$ & $5-35$ & $5-6$ & $6-11$ & $3-28$ & $4-53$ \\
\hline $\begin{array}{l}\text { Total } \\
\text { installed } \\
\text { capacity, } \\
\text { GW }\end{array}$ & $\begin{array}{l}15,9- \\
16,55\end{array}$ & $\begin{array}{r}17,25 \\
18,55\end{array}$ & $\begin{array}{c}16,45- \\
16,6\end{array}$ & $\begin{array}{l}15,8- \\
17,05\end{array}$ & $\begin{array}{r}16,65- \\
22,45\end{array}$ & $\begin{array}{l}18,1- \\
22,65\end{array}$ \\
\hline
\end{tabular}

The group 3 represents cost-effective solutions having minimum values of $C$ and relatively high values of other criteria. The structure of generating capacities features the dominance of thermal power plants.

The group 4 may be considered as "compromise" solutions. While $C$ values are similar to those of group 1, there is a convergence of $W_{F}$ and $P_{M A X}$ values, and $J_{D}$ increase. This group of solutions may be considered as an intermediate group between groups 1 and 2 .

Groups 5 and 6 are costly solutions with maximum values of $C$. They show however a more favorable combination of other criteria. The solutions of group 5 provide maximum reliability (minimum $J_{D}$ values), while those of group 6 ensure an optimal combination of $W_{F}$ and $P_{M A X}$ values. Both groups of solutions exhibit a substantial variance of gas turbine units used as stand-by capacity for reducing $J_{D}$, and wind power units used to reduce $W_{F}$.

In all solutions, the number of units of hydroelectric power plants takes discrete values, multiple to 5 for hydroelectric units of $100 \mathrm{MW}$ and multiple to 10 for hydroelectric units of $300 \mathrm{MW}$. This corresponds to predetermined limits of fixed number of units for hydroelectric power plants.

\section{Conclusion}

The advantage of multi-criteria formulations of the problem of justification of EPS development, as shown in this paper, is the possibility, in addition to addressing mandatory requirements for its performance and 
development, to compare the results of solving different options of EPS development in terms of reaching the goals specified as criteria. It becomes possible for EPS development decision-makers to evaluate the entire range of scenarios for such a development and to choose the only scenario that meets in the best way environmental conditions. For example, for this task subject to tight price constraints the appropriate choice of solutions from group 3 could be reasonable, while in case of environmental requirements priority those of group 1 should be preferred. Given the lack of comparability between studied criteria, such analysis of traditional one-criterion task for EPS development justification reveals to be impossible.

It should also be noted that it is possible to develop the statement (3) by including additional criteria that are relevant for EPS development justification. They are as follows: minimization of under-supply of energy, marginal costs, power imbalance of separate nodes of power plant, and others.

\section{References}

1. I.M.Volkenau, A.N.Zeiliger, L.D.Khabachev, Economics of electric power system formation (Energiya, Moscow, 1981)

2. D.S.Krupenev, S.M.Perzhabinsky, Automation and Remote Control, E 12, 2241 (2017)

3. N.Belyaev, A.Egorov, N.Korovkin, V.Chudny, E3S Web of Conferences, 139, 01004 (2019)

4. N.V.Korovkin, M.V.Odintsov, O.V.Frolov, Power Technology and Engineering, E 1, 75 (2016)

5. N.I.Voropai, S.V.Podkovalnikov, V.V.Trufanov and others, Justification for the development of electric power systems: Methodology, models, methods, and their use (Nauka, Novosibirsk, 2015)

6. E.Solovyeva, 2017 20th Conference of Open Innovations Association FRUCT (FRUCT20), DOI: 10.23919/FRUCT.2017.8071343 (2017)

7. N.Belyaev, A.Egorov, N.Korovkin, V.Chudny, E3S Web of Conferences (to be published)

8. V.A.Nepomniaschiy, Reliability of electrical power system equipment (Electroenergiya. Transmission and distribution, Moscow, 2013)

9. B.Duran, P.Odell, Clustering analysis (Statistica, Moscow, 1977) 